J. theor. Biol. (1975) 53, 205-214

\title{
Mate Selection-A Selection for a Handicap
}

\author{
AMOTZ ZaHAVI \\ Institute for Nature Conservation Research, Faculty of Life Sciences, \\ The George S. Wise Centre for Life Sciences, Tel-Aviv University, Israel
}

(Received 23 July 1974, and in revised form 2 December 1974)

It is suggested that characters which develop through mate preference confer handicaps on the selected individuals in their survival. These handicaps are of use to the selecting sex since they test the quality of the mate. The size of characters selected in this way serve as marks of quality. The understanding that a handicap, which tests for quality, can evolve as a consequence of its advantage to the individual, may provide an explanation for many puzzling evolutionary problems. Such an interpretation may provide an alternative to other hypotheses which assumed complicated selective mechanisms, such as group selection or kin selection, which do not act directly on the individual.

In his theory of sexual selection, Darwin (1874) tried to explain the evolution of characters such as the antlers of deer, the tail plumes of the peacock, the brilliant colouration of many birds and their fantastic displays and songs, by the cumulative effect of females preference for certain male types. He suggested that the disadvantages to male survival induced by such characters, are compensated for by more or better females preferring that individual to other males. But Darwin could not satisfactorily explain why females should prefer certain males. He just assumed that they prefer certain male types to others.

The theory of sexual selection aroused and still arouses much debate. There is a basic difficulty to be explained. On the one hand, it is a common observation that the most beautiful males of a bird species, or the deer with the largest antlers, are preferred by females, and, on the other hand, there is no simple explanation to suggest in what ways the preferred males should be of better quality than others. Wallace (1889), therefore, dismissed altogether the theory of sexual selection by mate preference while others, like Poulton (1890), defended it.

Fisher (1930) suggested that initially there was a correlation between the character preferred by the female and the quality of the male. This correlation when appreciated by discriminating females can account for the initial 
attractiveness of the male. Once sexual selection begins to have its effect, it generates a rapid chain of events in which the preference itself creates a selective pressure which accounts for the exaggerated development of the character and its additional attractiveness. Fisher suggested that (at the end of the process) males with the exaggerated sexually selected characters are more attractive to females not necessarily because they are better now than they were earlier but because they and their sons are more attractive to females. In Fisher's words "an additional advantage is conferred by the female's preference. The intensity of the second preference will itself be increased by selection so long as the sons of females excercising the preference most decidedly have any advantage over sons of other females whether this is due to the first or the second cause" (my own italics).

Fisher's argument that males bearing ornaments which might handicap them are attractive because their sons have a greater chance to be attractive, contrasts with his own statement that "tastes of organisms like other organs and faculties must be regarded as the products of evolutionary change governed by the relative advantage which such tastes may confer".

O'Donald's model (1962), in line with Fisher's argument, assumed that females evaluate males through a single character. It is obvious that with only one measurement at hand an exaggeration of the character, beyond its significance as an indicator for quality, will be undetected by females. But under most circumstances females probably select males by more than one character. In fact males advertise to females by voice, colour, movement and form, etc. An exaggeration of only one of these characters, without correlation to the quality of the males, should loose its effect by a negative selection. Any female which continues to prefer such a character will end up with a worse mate than females which choose males by all other characters except the exaggerated one. Generally it should be assumed that a character in a male is attractive to a female because it helps the female to select the better male.

Maynard Smith (1958) already remarked that "sexual selection will have evolutionary consequences only if those individuals which have characteristics which make them successful, in the competitions for a mate, are also fitter than the average as parents". Williams (1966) compared the process of mate selection to an "evolutionary battle of the sexes" which "fosters a skilled salesmanship among the males and an equally well-developed sales resistance in the females".

It is difficult to see how Maynard Smith and Williams could agree with Fisher, that a state of comparative stability may be reached, when the attractiveness of males may be the main reason why they are preferred (Fisher's second cause). 
I suggest that sexual selection is effective because it improves the ability of the selecting sex to detect quality in the selected sex. The selecting sex benefits because it can be assured of the quality of its mate, while the selected sex benefits because it can better advertise its quality and thus probably acquires more or a better mate. But both sexes also lose. Males lose by investing (time, energy, risks, etc.) in advertising. Females may receive less help from their mates and bear sons which are less fit to stand the pressure of natural selection (since they are also of the genotype which invests more in attracting females).

A survey of a variety of characters which were probably selected by sexual selection (through mate preference) makes it clear that probably all of them seem to confer a handicap on survival. The handicap inherent in the effects of mate preference could also be assumed as a logical conclusion. Before mate selection achieved its evolutionary effect the organism was in equilibrium with the pressures of natural selection. If the selective pressure of mate preference, which has no value to the survival of the individual, is added to the variety of selective pressures the effect must be negative. The larger the effect of the preference the more developed the character and the larger the handicap imposed. Hence a character affected by sexual selection should be correlated to the handicap it imposes on the individual. The antagonism which exist between the process of natural selection and sexual selection has already been mentioned by Darwin and Fisher. But they saw the antagonism as a by-product of the mechanism. My interpretation of sexual selection implies that sexual selection is effective only by selecting a character which lowers the survival of the individual. [An argument along this line was given by Emlen (1973) among several other arguments.] It is possible to consider the handicap as a kind of a test imposed on the individual. An individual with a well developed sexually selected character, is an individual which has survived a test. A female which could discriminate a male possessing a sexually selected character, from one without it, can discriminate between a male which has passed a test and one which has not been tested. The more developed the character the more severe was the test. Females which select males with the most developed characters can be sure that they have selected from among the best genotypes of the male population (Fig. 1).

An individual with a very good genotype but without a handicap is certainly fitter than a handicapped individual which otherwise possesses the same genotype. But since an individual without the handicapping marker does not advertise its quality, a potential mate cannot spot it. Females which choose by a sexually selected character compromise. They select a good quality male which is handicapped but they can be assured as to 


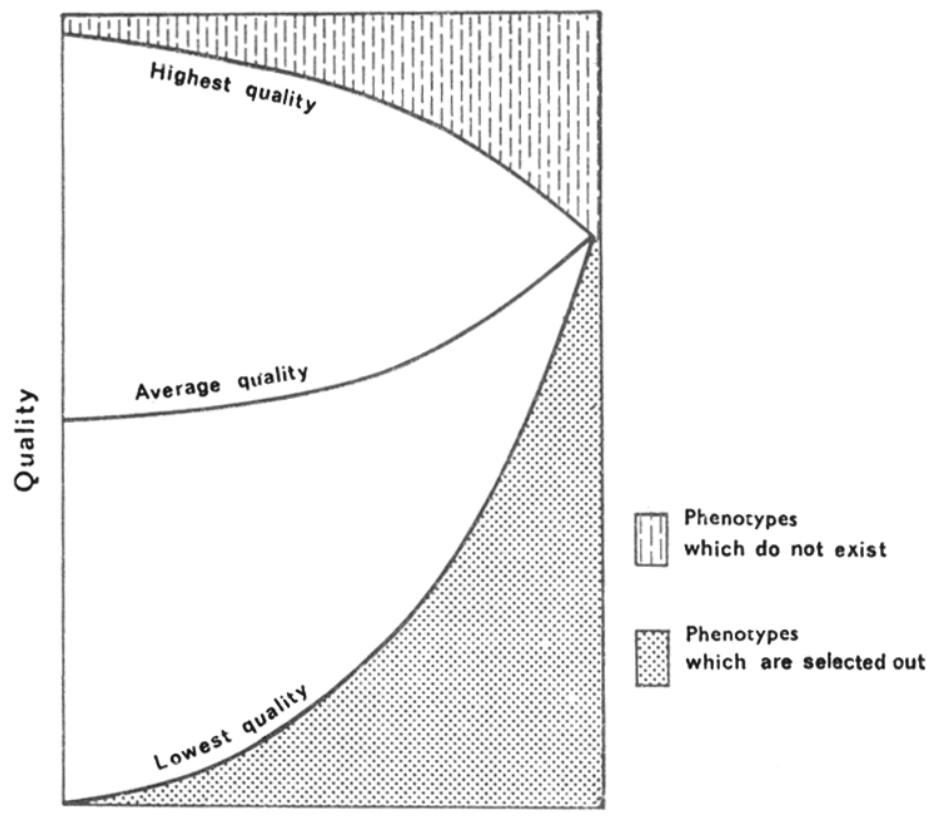

Magnitude of sexually selected character

Fig. 1. The effects of mate preference on the evolution of a sexually attractive character. Quality in the mate is plotted on the vertical axis while the size of the attractive character (which is considered to be a handicap) is plotted on the horizontal axis. At the intersection of the axes the character is of the size which fits best the selection pressure of natural selection. An increase in the character (hence in the handicap) eliminate low quality individuals (lower hatched area in the diagram). The selecting sex cannot distinguish quality among potential mates with equally developed attractive character. Note that the more developed the attractive character the higher the average quality of a potential mate.

their mate's quality. Sexual selection proceeds in producing an effect, as long as females benefit more from the assurance of the quality of their mates than they lose by mating with a handicapped mate, and as long as the males can survive the handicap. It is obvious that males which do not invest in parental care can spend more in order to pass the test of quality (Trivers, 1972; Selander, 1972).

In my model of sexual selection there is no need to assume any special genetic linkage between the marker of quality and the quality of the individual. Since whenever the marker is present in a phenotype, the handicap it has already imposed is a proof that the phenotype and hence very likely also the genotype is above a certain level of quality marked in the model by the lower curve. 
Since any genetic linkage between a marker and quality is open to a change and hence to a bluff (i.e. low quality individuals may be tagged by high quality marker) the test of the handicap is a simple way to exclude bluff.

The effects of sexual selection should vary, as suggested already by Darwin, and have to be "compatible with the existence of the species". Hence some species and often one of the sexes (which invest more in parental care) cannot be easily pushed into a handicap since the pressures of natural selection are too tight. In these cases mate selection might be achieved either through an easier test, with a smaller handicap, or without any at all. In the last case a mate may be selected but "sexual selection" cannot operate. Under such circumstances mate selection is probably less reliable and takes more time (Zahavi, in prep., also see below, the comparison of monomorphic and dimorphic plumage in birds).

Darwin has already pointed out the difficulty in judging in any one particular case how much of a character developed as a consequence of natural selection and how much by sexual selection. The effects of both types of selection are often mixed from the beginning, since sexual selection preferably acts on characters which have already been correlated with quality. Natural selection can also affect characters which have evolved by sexual selection, if these gain some new function. Hence it is almost impossible to separate clearly the effects of natural selection which are responsible for the adaptive value of the character from those of sexual selection which developed its advertising component. A discussion of the effect of sexual selection will therefore have to be speculative.

The discussion of a sample of characters, which follows, aims to present some of the possible effects of mate preference. The value of the characters discussed is explained by the tests they impose on the individuals which bear them. It is clearly understood that the evolution of all these characters may be explained by more than one hypothesis. The discussion of the examples is given as a model of yet another way to consider the characters. To determine in any case which of the alternatives is the true explanation, calls both for a detailed examination of the facts and for further experimental confirmation. The cases are not presented as a proof of the handicap principle. My aim is to call the attention to the possibility that the value of many characters may reside in their action as testing devices.

Characters which attract the other sex cannot always be separated from those which intimidate rivals of the same sex. Generally the effects of mate preference should be much larger than those which result from intrasexual conflicts. The reasons for all this will be discussed elsewhere. Fisher (1930) came to the same conclusion when he stated that male ornaments acquired 
through male-male conflict may be striking but could scarcely ever become as extravagant as characters which develop to impress a potential mate.

In many species of birds, the female is cryptic while the male is colourful. The accepted explanation is that females cannot withstand the extra predation pressure involved in colourful plumage since they have to attend more to the nest. The colourful plumage of the male is supposed to attract females and intimidate other males. But there are as many species in which both sexes are cryptic. Males of such species also mate and fight their rivals. The interesting question is why should some species "find it better" to be excited or intimidated by the more colourful males? This will only make sense if colourful males are of better quality. I suggest that a mature, colourful male has already proved itself to be of a better quality (than one with cryptic plumage) since it has already withstood the extra predation risk involved in its plumage. Hence colourful plumage is a mark of quality, and it is to the advantage of the females to be attracted by colourful males. It is probably more difficult to discriminate quality among mates with cryptic plumage. Another way to evaluate the quality of a cryptic male is to observe it over long periods. Species which have environmental conditions allowing for prolonged periods of pair formation, or others which cannot put males to a high predation risk probably, choose such a strategy. This may explain Lein's (1973) finding that monomorphic species of warblers take longer to pair than sexually dimorphic species with colourful male plumage. This may be the reason why northern duck species, whose short breeding season demands a short period of pair formation, evolved striking male plumage. Where time for breeding is short and where males do not participate as much in parental care, males evolve the colourful plumage as a result of female preference. The male's colourful plumage then serves as a mark of quality and helps females choose good quality males.

Mayr (1972) suggested that the striking male pattern of drakes reduces interspecies hybridization. Therefore populations, which do not face a hybridization risk, loose their bright male plumage. But why did not duck species evolve other isolating mechanisms less risky than bright plumage patterns? An alternative hypothesis to that presented by Mayr, is that the bright male colouration of northern duck species evolved first as an indicator of the quality of the drake. The colourful plumage, which probably varied geographically according to various environmental selective pressures, eliminated hybridization between duck populations to the extent that other isolating mechanisms were not necessary and hence could not evolve. The above hypothesis, as to the adaptive significance of the colourful male plumage, is not presented as conclusive evidence to prove the principle of testing a mate through a handicap. It is presented to show yet another 
way to consider the known facts. The same is also true for the rest of the cxamples which follow.

The excessive tail plumes of the peacock which seem to attract the females are obviously deletorious to the survival of the individual. The more brilliant the plumes the more conspicuous the male to predators, and the longer the plumes the more difficult it may be for the male to escape predators or to move about during everyday activity. Hence, only the best males would be able to sustain the handicap. Therefore, if females select for males handicapped by long plumes, they select for quality. It would certainly be better for females to choose high quality males which were not handicapped by the plumes. Therefore we have to assume that a discrimination for quality is more difficult without the test of the plumes.

Many, if not all, sexual displays endanger their performers. Many of them seem to be designed specifically for that purpose. Warblers sing out of cover. Lek species dance daily in the open in the same places. The extra risk which is taken cannot be just to communicate the whereabouts of a malc ready to mate. Males probably try to communicate their quality. Since good quality birds can take larger risks it is not surprising that sexual displays in many cases evolved to proclaim quality by showing the amount of risk the bird can take and still survive. If displays had evolved to communicate in the most efficient way the whereabouts of a bird, in saving energy and reducing predation hazard, as many alarm calls have evolved (Marler, 1955), they would not serve as markers of quality.

Although in this discussion the female is usually referred to as the selecting sex and the male as the selected sex, it should be born in mind that both sexes may select and sexual selection may get its effect on both sexes, as is the case in some monomorphic species. Sometimes the female is more affected by sexual selection as is the case in quite a number of species (Selander, 1972; Trivers, 1972).

Coulson (1968) investigated the role of mate preference in a breeding colony of kittiwakes. These birds fight ferociously with one another to occupy central territories. Coulson found that birds which breed in the centre of the colony are of a better quality, as judged by their reproductive performance, than birds breeding in the periphery of the colony. Hence a female which pairs with a male on a central territory, pairs with a good quality male. Patterson (1964) found that centrally located territories in the blackheaded gull are more protected from predators so that the fight for central territories, in that case, could be explained as a consequence of predation pressure. However, the kittiwakes nest on cliffs and are comparatively free of predation. Many well-protected sites in the colony are vacant when the ferocious fight for the central territories is going on. A fight for central sites 
in colonies is found also in large sea birds like the gannets which nest on islands free from predators. An initial tendency to breed together, possibly in order to get information about food (Ward \& Zahavi, 1973), may give rise to some fights for centrally located sites, since in the centre the birds are more protected and perhaps get more information. Such fights, however small, may further evolve through mate preference to serve as an index of quality. That particular method of testing mate quality has probably evolved since the ability of colonial birds to fight one another for food is important. Also, only the better quality birds can depart from offshore feeding grounds early in the season and succeed in occupying the central places on the cliffs. Central birds handicap themselves when they invest time and energy in the fight for the centre but they are compensated by better quality mates.

Territorial behaviour presents an interesting problem since often males claim territories which seem to be much larger than the birds may need. It is not easy to see the selective agent for large territory size. Wynne-Edwards (1962) suggested that its adaptive significance is to regulate levels of food supply to population size. He argued that with a large territory the bird insures the persistence of food supplies to future generations. Such altruistic behaviour calls for group selection theory. Alternatively, the selection for a mate may have its effect in this situation. Often males which occupy small territories seem to be less successful in acquiring a mate (Watson, pers. comm.; Zahavi, unpublished observation on Oenanthe). Since a small territory probably cannot easily support a family, a tendency to select a mate which occupies a large territory may increase through mate preference to the extent that males occupy territories much larger than their immediate needs. A fight for a larger territory must be more difficult than a fight for a small one; hence, males which succeed in occupying large territories should be of a better quality than males which occupy small territories. Females which select such males also select for quality. The conservation of food supply for the population may be a side effect rather than the causal mechanism which selects for territory size. O'Donald (1963) already suggested that sexual selection may be involved in territorial behaviour but he understood somewhat differently the selective mechanism involved.

The contrasting black and white plumage displayed by many adult sea birds, especially when flying and diving, serves in communication since they attract more individuals to food sources. The evolution of the bright "altruistic" plumage and its retention in a population is difficult to explain. In a predominantly altruistic population, any individual with "selfish" dull plumage may do better than an "altruistic" one, since it will benefit from sources of food found by all other birds and will not have to share food 
found by itself. An indication that mate preference may be involved is furnished by the fact that only adult birds have the "altruistic" plumage while immature ones, even when 2 years old, have "selfish" plumage. The advantage in selecting a mate with "altruistic" plumage is that it selects an individual which has already passed the test. This test is meaningful because when breeding in colonies birds have to compete daily over food.

An alternative explanation of the altruistic behaviour may be on the lines of reciprocal altruism (Trivers, 1971). Such an explanation calls for a mechnism of punishments to guard against selfish individuals. But if mate preference is responsible for the selection of the altruistic character then no punishment is needed and "altruism" is compensated for by a better quality mate.

It is reasonable to expect mate preference in all sexually reproducing organisms. As a consequence (if natural selection allows) one would expect also the evolution of markers for the differentiation of quality in individuals. O'Donald (1963) suggested that altruistic behaviour may function as a marker for quality and that it is selected for through mate preference. Unfortunately that idea has not been followed, perhaps because it was believed that the evolution of exaggerations (handicaps), through mate preference, is only a by-product of a "run-away" process (Fisher, 1930; O'Donald, 1962). When the handicap caused by mate preference is considered as the key to the selection process rather than its byproduct (Fig. 1) it is reasonable to expect handicaps, and consequently also altruistic behaviour, to be widespread phenomena.

Some of the arguments in support of the handicap principle in the evolution of mate preference are given by Emlen (1973), but at the same time he accepted the possibility of a random fixation of such characters. He suggested also that in some cases the importance of the character is in the ability of the animal to waste its energy to show off its prowess. But according to him the special means by which it shows its prowess have often been accidentally determined.

The handicap principle as understood here suggests that the marker of quality should evolve to handicap the selected sex in a character which is important to the selecting sex, since the selecting sex tests, through the handicap, the quality of its potential mate in characters which are of importance. Hence the attracting character which evolved through mate preference should be related to the special ecological problems of the species. The adaptive significance of the attracting character should lower the fitness of the selected sex in relation to the main ecological problems of the species. The selecting sex should be attracted by a marker only when the handicap it imposes on its mate and its offspring is smaller than the advantage gained 
by securing a better (tested) mate. This evolutionary mechanism need not be different in its rate from any other selection process. The attracting characters should evolve only as a consequence of an environmental change which requires a different kind of test.

I should wish to thank Prof. R. K. Selander for much encouragement and criticism and Prof. Maynard Smith and Dr R. Trivers for discussing the idea. Dr A. Terkel, Dr Y. Terkel and my wife Dr Avishag Kadman-Zahavi were of much help both in discussing the idea and in improving its presentation. Thanks are due to $\mathrm{Z}$. Tamir for typing the manuscript.

\section{REFERENCES}

Coulson, J. C. (1968). Nature, Lond. 217, 478.

DARWIN, C. (1874). The Descent of Man and Selection in Relation to Sex. 2nd edn. London: John Murray.

EMLEN, J. M. (1973). Ecology, an Evolutionary Approach. Reading, Massachusetts: Addison-Wesley.

Fisher, R. A. (1930). The Genetical Theory of Natural Selection. Oxford: Clarendon Press.

LEIN, M. R. (1973). The biological significance of some communication patterns of wood warblers (Parulidae). Unpublished Ph.D. Thesis, Harvard.

MARLER, P. (1955). Nature, Lond. 176, 6.

Maynard Smith, J. (1958). In A Century of Darwin (S. A. Barnett, ed.). Cambridge: Harvard Univ. Press.

MAYR, E. (1972). In Sexual Selection and the Descent of Man (B. Campbell, ed.). Chicago: Aldine Publ. Co.

O'Donald, P. (1962). Heredity 17, 541.

O'Donald, P. (1963). Heredity 18, 361.

Poulton, E. D. (1890). The Colours of Animals: Their Meaning and Use Especially Considered in the Case of Insects. London: Kegan Paul, Trench Trubner \& Co.

Patterson, I. (1964). Timing and spacing of broods of the black headed gull Larus ridibundus L. Ph.D. Thesis, Oxford.

Selander, R. K. (1972). In Sexual Selection and the Descent of Man (B. Campbell, ed.). Chicago: Aldine Publ. Co.

TrRVERS, R. L. (1971). Q. Rev. Biol. 46, 35.

Trivers, R. L. (1972). In Sexual Selection and the Descent of Man (B. Campbell, ed.). Chicago: Aldine Publ. Co.

Wallace, A. R. (1889). Darwinism: An Exposition of the Theory of Natural Selection with Some of its Applications. London: MacMillan \& Co.

WARD, P. \& ZAHAVI, A. (1973). Ibis 115, 517.

Williams, G. C. (1966). Adaptation and Natural Selection: A Critique of Some Current Evolutionary Thought. Princeton: Princeton Univ. Press.

Wynne-Edwards, V. C. (1962). Animal Dispersion in Relation to Social Behaviour. Edinburgh: Oliver \& Boyd Ltd. 